\title{
SEA LEVEL ANALYSES OF PSMSL SERIES BY PROXIMITY AND COLLINEARITY COEFFICIENTS
}

\author{
Afrânio Rubens de Mesquita, Carlos Augusto de Sampaio França and Marco Antonio Corrêa
}

\begin{abstract}
Annual mean sea level data distributed by PSMSL (Permanent Service for the Mean Sea Level) of IAPSO (International Association for the Physical Sciences of the Oceans) were analysed in the search for global sea level co-variants and invariants. The correlation coefficient $\rho$, taken as a measure of collinearity $\rho_{c}$ in time series, was shown to depend on the ratio of two variances and then invariant with the inclination $\beta$ of the regression line $y_{r i}\left(t_{i}\right)=\tan (\beta) x_{i}+\alpha$, $\alpha$ the intercept, relative to the Cartesian coordinated axes. Also invariant with the trends $\beta_{t}$ is the distance $\ell_{i}$ of the discrete data points $\left(x_{i}, y_{i}\right) i=1,2 \ldots, n$, to the regression straight line previously calculated. The mean over all $\ell_{i}$ was taken as a measure, a coefficient of proximity $\ell$ of each series. Analysis of the two coefficients allowed the definition of a variable $F=\rho_{c} \times \ell$ whose values, in consequence, are also invariants with the trends $\beta_{t}$ of the individual series. The same can be said about the $F$ distribution shape, in a plot that allowed the comparison of the $F$ values of all ports round the globe. Ports as of Cananeia (Brazil), San Francisco (USA), Brest (France), Antofagasta (Chile), and Takoradi, from Gana (Africa), occupy very distinct and relatively permanent positions in the plot, which, for longer series, are also invariant with their length in years. Analyses of a plot of $\rho_{c}$ and $\beta_{t}$ showed also that although they are statistically mutually invariants, their values, calculated from PSMSL series, seem to be distributed as covariant variables. All mentioned invariance and co-variance seem related to what appears to be a limit globally imposed on the variability of planetary sea level series from all ports of islands and continents, by the Earth's gravity field. The study of the induced co-variance between $\ell, \rho_{c}$ and the $F$ values, with the trends, may help to unveil the characteristics of the constraints on the planetary relative to sea level series.
\end{abstract}

Keywords: collinearity coefficient, proximity coefficient, PSMSL series, regression line, planetary series, trend invariants.

RESUMO. Valores médios anuais de nível do mar distribuídos pelo PSMSL (Serviço Permanente para o Nível do Mar) da IAPSO (Associação Internacional para as Ciências Físicas dos Oceanos) são analisados na procura de invariantes globais do nível do mar. 0 coeficiente de correlação $\rho$, admitido como uma medida da colinearidade em séries de tempo $\rho_{c}$, foi mostrado ser dependente da razão de duas variâncias e então invariante com relação à inclinação $\beta$ da reta de regressão relativa aos eixos coordenados cartesianos. Também invariante com a inclinação $\beta$ é a distância média $\ell$ dos pontos discretos da série até a reta de regressão. A distância média é tomada como uma medida, como um coeficiente de proximidade dos pontos da série à reta. A análise desses coeficientes $\left(\rho_{c}\right.$ e $\left.\ell\right)$ e sua invariância com relação à rotação do sistema de coordenadas permitiram a definição de uma variável $F=\rho_{c} \times \ell$ que é também invariante com o sistema e pode ser tomada como uma constante de cada série, que caracteriza cada série do conjunto de séries planetárias e, em consequência a distribuição dos valores $F$ contidos nas series PSMSL. Nessa distribuição os portos de Cananeia (Brasil), São Francisco, (EUA), Brest (França), Antofagasta (Chile) e Takoradi, Ghana (África), ocupam posições bastante particulares, relativamente permanentes e invariantes com o comprimento das séries. Análises das variáveis colinearidade $\rho_{c}$ e tendências $\beta_{t}$, mostraram também, que embora elas sejam estatisticamente mutuamente invariantes, seus valores calculados a partir das séries PSMSL, são linear e globalmente distribuídos como variáveis covariantes. Isso é interpretado como devido a limites naturais geofisicamente impostos nas séries planetárias. 0 estudo dessa dependência induzida entre $\rho_{c}$, $\beta_{t}, \ell$ e $F$, pode, eventualmente, ajudar a descobrir as características desses vínculos planetários.

Palavras-chave: coeficiente de colinearidade, coeficiente de proximidade, séries do PSMSL, reta de regressão, séries planetária, tendências constantes.

Instituto Oceanográfico da Universidade de São Paulo, Cidade Universitária, Butantã, 05508-900 São Paulo, SP, Brazil. Phone: +55(11) 3091-6564 - E-mails: ardmesqu@usp.br; cafranca@usp.br; mcorrea@usp.br 


\section{INTRODUCTION}

The PSMSL (Permanent Service for the Mean Sea Level) of IAPSO (International Association for the Physical Sciences), series of sea level data, is a world wide distributed set of data, measuring the sea level, as well as, altogether, the level of Earth's crust. In this communication they are world wide values of mean annual series of relative sea level (not series of absolute sea level values) and carry some geophysical information, which only may become evident from the analysis of the entire set of data. Figure 1 shows the world distribution of the PSMSL Stations around the planet.

The measurements of sea level at these stations are permanently taken by the different authorities of the coastal nations, under the IOC (Intergovernmental Commission of Oceanography) of UNESCO. The IOC publishes Manuals and Guides (IOC, 2006), where a thorough description of how to measure and analyse the sea level data are presented.

In what follows a short review of the figures and the pertinent early communications to several scientific meetings are reproduced, showing the various ideas that lead to the search of invariants and co-variants characteristics of sea level data of this communication. Particularly the interpretation of co-variance from statistics, meaning here a dynamical (or other) connection and the opposite relation, the invariance from statistics, meaning here no possible dynamical connection between variables.

A figure (regression coefficient $\times$ correlation coefficient) of truly random synthetic sea level data was produced for comparison with similar figure of the real data. The comparison showed clearly that real long term sea level data can not be identified as random, for example, as fluctuations related to the random action of the atmospheric variables on the oceans.

If annual mean sea level data can not be interpreted as random to what can it be? Following the recommendation of the São Paulo 1997 meeting of the RBGf, further work on the plot of trends and correlation values was then done, showing that the diminishing size of the standard deviation trends towards zero, at the zero of the plot, found in South American and African, the Brazilian series included, was also true for the entire PSMSL set of sea level data. The plot of the random data generated by the computer, on the contrary, exhibited, by birth, no diminution of the error bars towards the zero value of the plot confirming the previous understanding.

Besides that, in the vicinity of zero, the mean values of trend of the bins were displayed, in the positive and negative sides of the plot, along two straight lines having different inclinations. The figure showed that the mean trend values, from all ports with similar correlation values, were set in bins that fit well in two straight lines, whose inclinations indicate a negative value for the global data trend. So, the mean sea level data trends were not from a random data, as previously supposed, but, and surprisingly, they also could be linearly put along two straight lines i.e. they were co-variant variables.

The linear distribution of trends indicated a linear correspondence (covariance) between trends and correlation values of the series, but was this correspondence (covariance) coming from what says the theory of statistics? The answer to this question lead us to derive the coefficients of collinearity and proximity, which were found to be independent (invariant) with the inclination of the particular regression line they were related to. Then it was clear, that, contrary to what says the theory of statistics, they must be, for the global sea level data, taken as dependent (covariant) variables.

How could they be displayced along two linear lines? To go further with attempts to answer the questions, from the collinearity and proximity coefficients, a product was devised, in order to combine them into a single variable. The product, as a consequence, was also independent (invariant) with the trends of any sea level series and it was also found to be independent (invariant) with the length (time) of the series. The histogram of their product is, in consequence, a static figure of each port over the planet, as it is invariant with the trends, as well as, with the length of the series (the time), in the time being. This, somehow, validates the infringement of the theory.

The answer to the above question is hard to produce now, but, it appears from the above reasoning that, eventually, the answer may be related to not known global crustal motions connected to the material of the Earth's mantle.

\section{Background knowledge}

The features of the present analysis were first mentioned in Mesquita \& Leite (1986) and in a more elaborated text by Mesquita (1994). They were discussed at several meetings (Mesquita et al., 2001a, 2001b, 2003a, 2003b) of the OESTE (Escola de Séries Temporais e Econometria - Associação Brasileira de Estatística), meetings of the PSMSL and also at meetings of GLOSS (Global Observing Sea Level System), a program of IOC of world wide almost evenly sea level stations for measuring the sea level.

They were also outlined in (Mesquita, 2001) and in the AfroAmerica GLOSS News (Mesquita et al., 2002), showing the relationships between parameters of time series data of Figure 2, such as trends $\beta_{t}$, angles $\beta$, values of regression coefficients $\beta_{0} \tan (\beta)$, distances $\ell$ of data points to the derived regression line, and correlations $\rho$. The aim of them all was of a better under- 


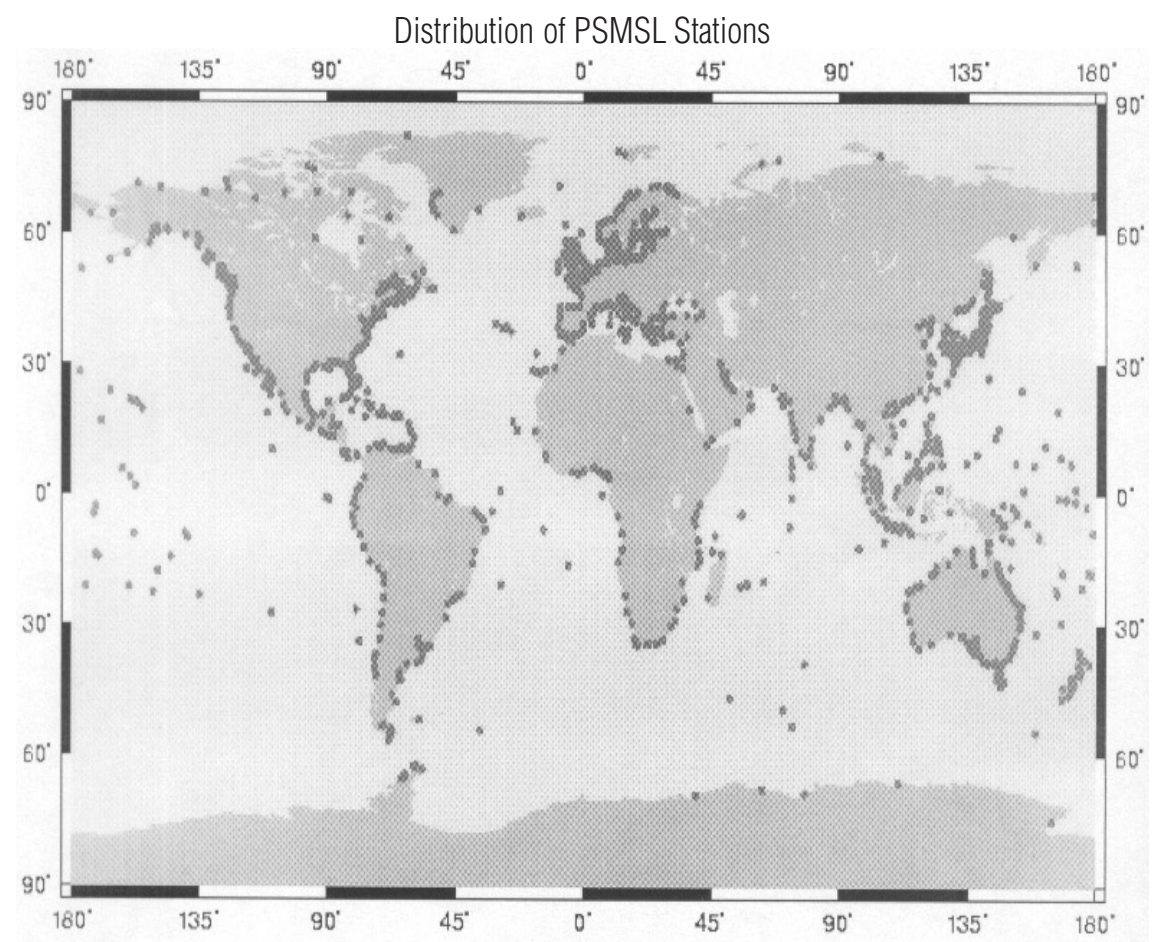

Figure 1 - PSMSL (Permanent Service for the Mean sea Level) stations positions represented in all continental borders (Woodworth \& Player, 2006).

standing the geophysical information in the set of PSMSL relative annual sea level series (Spencer \& Woodworth, 1993), taken here as a planetary data set. For that the set was initially compared with several other computer made synthetic series.

The plot against the time of annual values of the planetary series have trends, $\beta_{t}$ that appear to be physically constrained by the planet Earth, relative to its surface, to maxima trend values, say, within $\pm 40 \mathrm{~mm} / \mathrm{year}$, as the planet, in the scale of years, does not change its volume or shape abruptly as a whole.

Having this in mind, 5,500 noisy synthetic ordinary time series, with 5 to 60 equivalent years lengths, were built, forced to acquire regression coefficient $\beta_{0}$ values within about \pm 40 . From them, the synthetic distances $\ell$, (the proximity of the data points to the straight line) and the synthetic correlation coefficients $\rho_{c}$, (the collinearity of the data points along the shape of the straight line) were calculated. The plot of the pairs, $\beta_{o} \times \rho_{c}$ is shown in Figure 3.

Similarly, the actual proximity coefficients $\ell$, the actual collinearity coefficients $\rho_{c}$, and the corresponding trends $\beta_{t}$ from real mean annual values of 837 PSMSL planetary series, with different lengths, greater than 5 years, were also calculated for comparisons and are shown in Figure 4.

The overall results of the comparison show that, while for the synthetic series collinearity $\rho_{c}$ is invariant with the values of the $\beta_{0}$ (Fig. 3), the whole set of real constrained planetary series have collinearity values that seem globally covariant with the trends $\beta_{t}$ (Fig. 4), while keeping their original invariance of the sea level series. In consequence the plot of $\beta_{t} \times \rho_{c}$ for planetary series revealed another straight line, that should have not been followed either by $\beta_{t}$ or $\rho_{c}$, as in fact they seem to be doing, and this is interpreted as the unveiling of an Earth's free response, that is in printed on the entire set of constrained planetary series used.

This was noticed by Mesquita \& Leite in their communication of 1986 and in Mesquita (1994) showing that the standard deviations of $\beta_{t}$, in each bin they were separated, near the value zero, tend to vanish, as can also be inferred from Figure 4 . From zero, they depart to the positive and negative sides of the figure, along two new straight lines with different trends $\beta_{1}=$ -1.1 (cm/year) $/ 1$ (collinearity) and $\beta_{2}=+0.9$ (cm/year) $/ 1$ (collinearity), giving a ratio of $R=-11 / 9=-1.2$. See Mesquita et al., 2013 (this edition).

As $\ell$, the proximity coefficient and $\rho_{c}$, the collinearity coefficient for a given planetary series, are both invariant with the trend $\beta_{t}$, (as also are the $\ell$ and $\rho$ values of the synthetic series relative to $\beta_{0}$ ), a function $F=\ell \times \rho_{c}$ was defined, that is also invariant with $\beta_{t}$ and $\ell$. The $F$ function is, with the above ratio $R$, another characteristic of mass and gravity of constrained planetary series. 


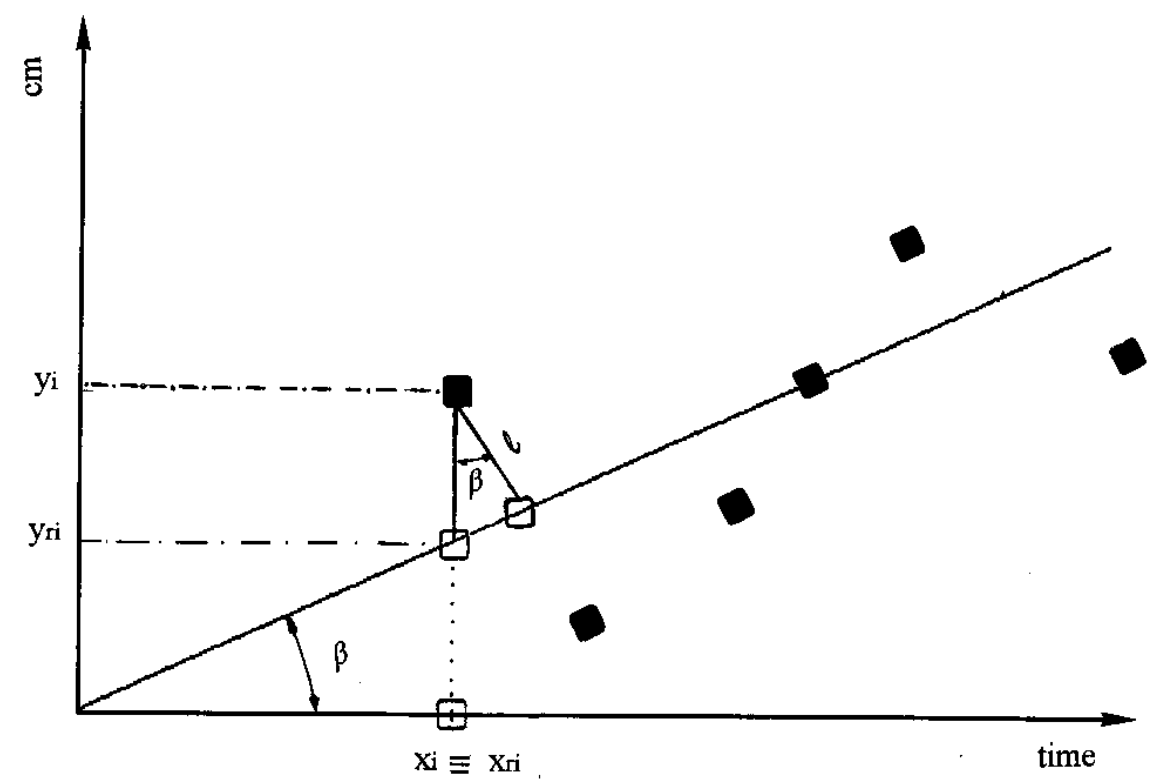

Figure 2 - The regression line and its generating points (black squares). $\ell_{i}$ ( $\mathrm{cm}$ or $\mathrm{mm}$ ) are the distances of the points $\left(x_{i}, y_{i}\right), i=1, \ldots, n$, to the regression line. Their projections on the straight line $\left(x_{r i}, y_{r i}\right)$ are represented by white squares. $\beta$ is the inclination of the regression straight line relative to the $x$ (time) axis. $\beta=\tan (\beta)$ is the regression coefficient.

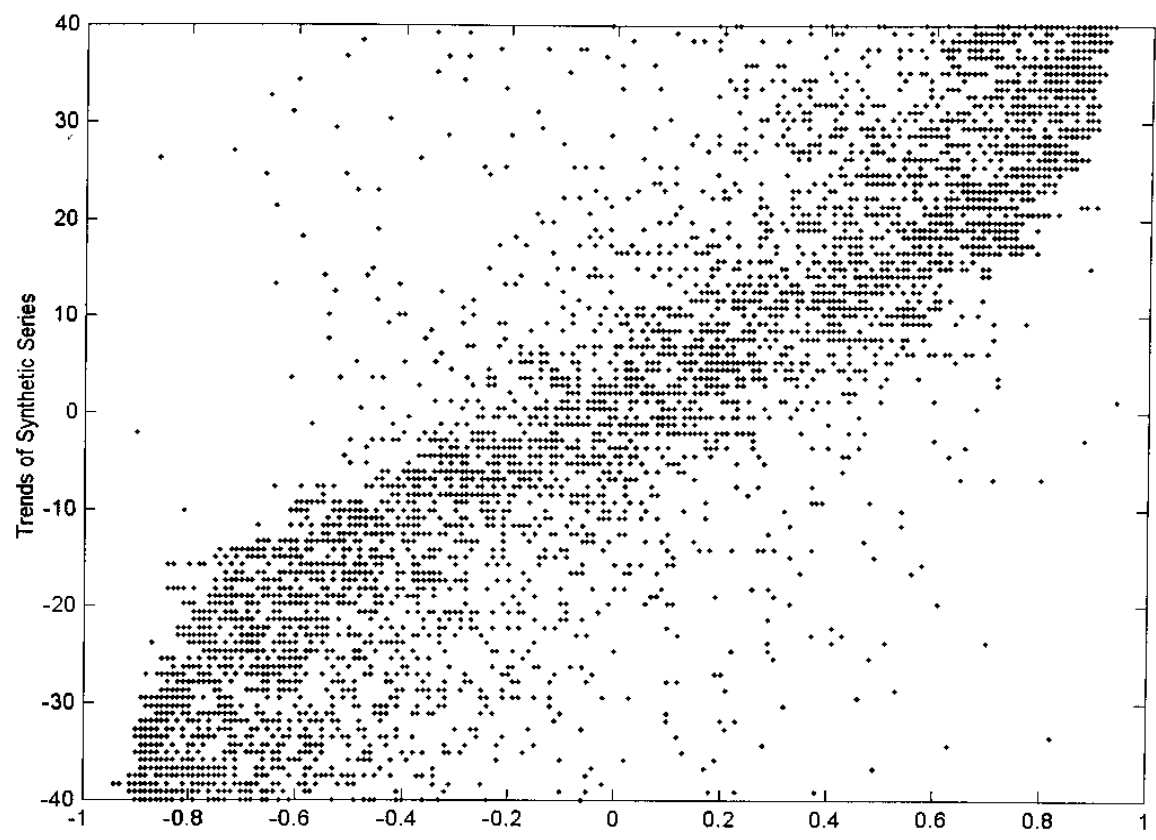

Figure 3 - Synthetic values of correlation coefficients against the corresponding values of regression coefficients.

The distribution curve of $F$ (Fig. 5) may have, with the glaciations, an evolving timely constant shape, which is a characteristic of the planet Earth, where the few identified, ports of Africa, Europe and the Americas of this communication, as well as, all the others, should hold, in the present days, relatively permanent positions.

\section{MATERIAL AND METHODS}

Given a circular line, (a circumference), with a set of points that normally distributed, surrounds it, a sort of correlation, which measures how close or disperse are the points from the circular line, may be formulated. The correlation, with this meaning 


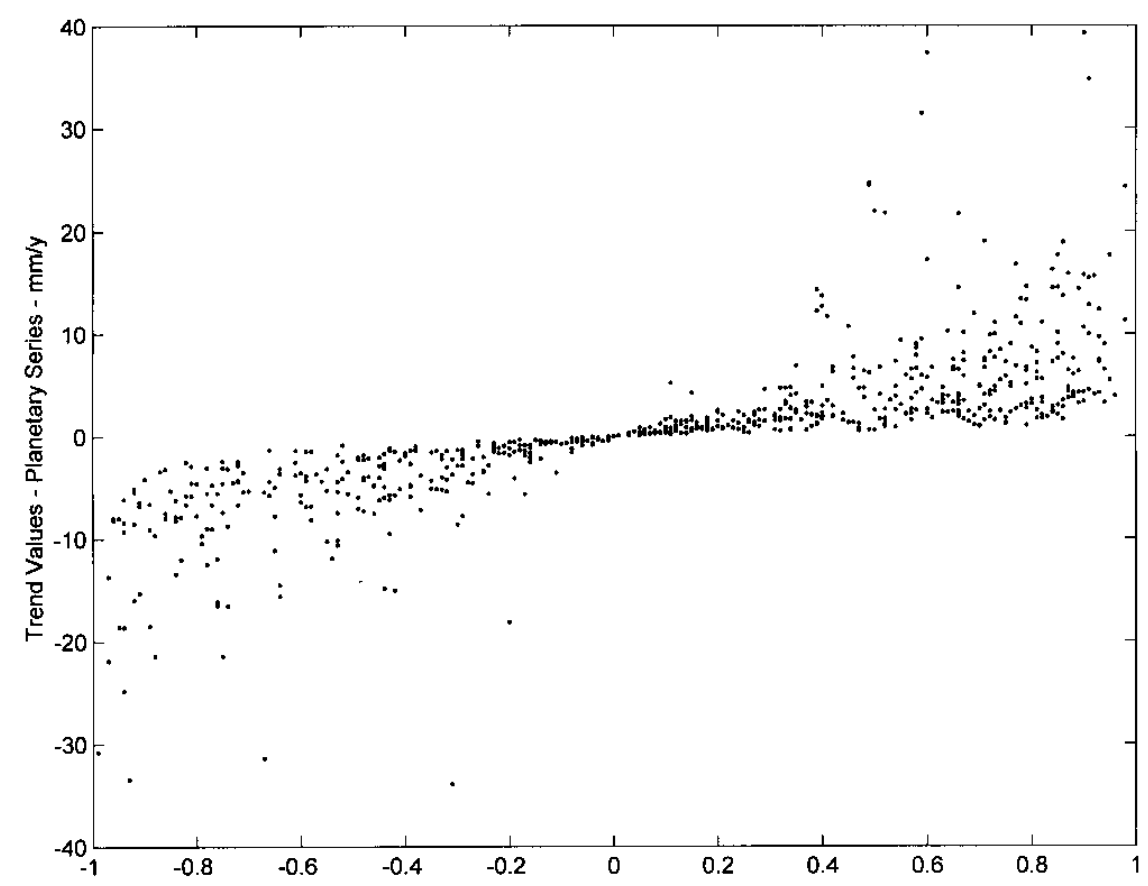

Figure 4 - Correlation coefficients plotted against the correspondent trends of real series of PSMSL mean annual sea level data.

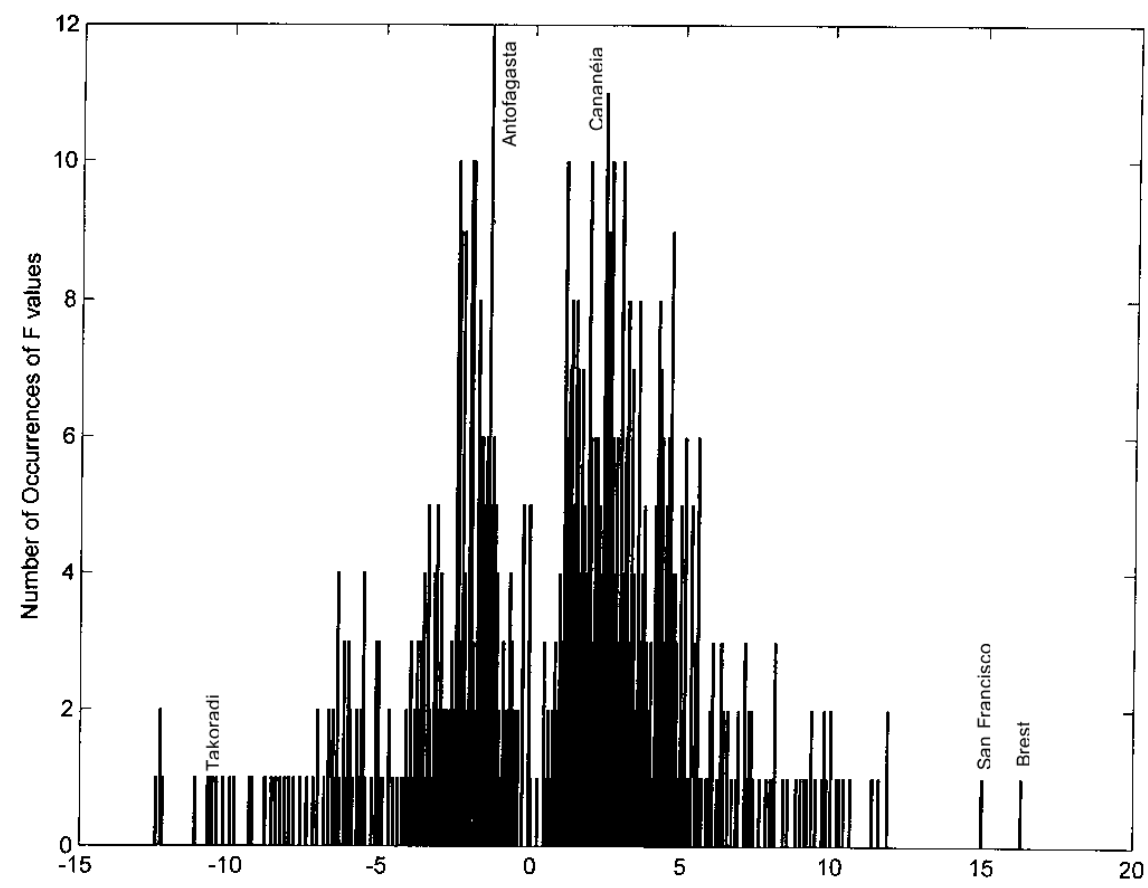

Figure 5 - Histogram of $F$ values for the PSMSL series.

(correlation as a measure of proximity of the cloud of points to the circumference), is clearly invariant with the rotation of the system of Cartesian co-ordinates fixed, for example, in its centre, as the mean distance of all points to the circumference is a geometric property of the space time and it will not vary with a variable orientation of the co-ordinate axis.

By rectification, the circumference, (or any other closed curve) and the accompanying set of points can be transformed into a 
segment of straight line, a one dimensional figure, with its bidimensional accompanying set of points (Fig. 2). Assuming in a plane, a one dimensional normal distribution of the point's distances to the line, the normalized standard deviation of the distances of the set can be devised. It can be realized in this circumstance that the standard deviation of the distances of the points to the central line will be great (when the points are totally apart from the line) and zero (when all points lye on the line) and may be taken as a measure of the correlation of the surrounding set of points with the straight line.

\section{Coefficient of proximity}

In fact, from Figure 2 it can be seen that from the Cartesian coordinates of a point $\left(x_{i}, y_{i}\right)$, belonging to the cloud of points and from the inclination $\beta$ of its straight line, it is possible to infer the co-ordinates $x r_{i} ; y r_{i}$ of its projection on the line, and the distance of length $\ell_{i}$ so that:

$$
\ell_{i}=\left(y_{i}-y r_{i}\right) \cos \beta,
$$

making in (1) the substitution $y r_{i}=x_{i} \tan \beta$, one gets:

$$
\ell_{i}=y_{i} \cos \beta-x_{i} \sin \beta,
$$

As one can see from (2) $\ell_{i}$, as Euclidean distances, are necessarily invariants with the inclination $\beta$ and the corresponding co-ordinates of the point $\left(x_{i} ; y_{i}\right)$, as the system of reference rotates in the plane of the figure. For any variation of $\beta$ there will be changes of the co-ordinates $x_{i}$ and $y_{i}$ so that the above expressions satisfy the physical distance $\ell_{i}$ as constants.

By taking the mean over all distances $\ell_{i}=1,2, \ldots, n$ of an annual sea level data set, of a given PSMSL series, the coefficient $\ell$ of proximity of that series was obtained.

\section{Coefficient of collinearity}

However, from Figure 2 one sees that the correlation can also be taken as a measure of linear covariance between the set of points that surrounds the line and the ones belonging to it. This off course if they, the points belonging to the straight line, can be treated, somehow, as a random variable. In the special case of time series, in which $x_{i}=t_{i}, i=1,2,3, \ldots, n$, they can not be taken, by any means, as a random variable. That makes these inferences not so clear and here on, because of that, the name of collinearity is chosen as more appropriate to nominate this sort line, i.e., the correlation of values of a random variable $y\left(t_{i}\right)$ with those on the straight line $y_{r i}\left(t_{i}\right)=\beta_{o} t_{i}+\alpha$.

The known concept of correlation is of a measure of linear dependence between two random variables (Jenkins \& Watts, 1968) and, in the limiting case, when the correlation is one, there is an exact linear relationship of the form

$$
y_{i}=\tan (\beta) x_{i}+\alpha,
$$

where $\beta_{o}=\tan (\beta)$ is the regression coefficient and $\alpha$ is the intercept, $i=1,2,3, \ldots, n$.

When the correlation $\rho$ is zero there is no linear covariance between the two random variables. In the case for correlation zero, $\beta_{o}=\tan (\beta)$ may assume any value from $-\infty$ to $+\infty$ and the inclination $\beta$ of the line will take any value within $\pm \rho / 2$ radians.

The question which arises now is if the two ways of interpreting the correlation, as a measure of the proximity $\ell_{i}$ of the cloud points to the line, or as a measure of the collinearity $\rho_{c}$ of the points of the cloud, can be both invariant with the rotation of the co-ordinate system, as already does the first interpretation.

\section{Collinearity and correlation}

To examine the second case let $X$ and $Y$ be two random variables with values $x_{i}$ and $y_{i}$ and that one wishes to approximate the values of $Y$ by a linear combination of the form: $y_{r i}=\alpha+$ $\beta_{o} x_{i}$. Following the method of minimum squares, the differences of the random variable $Y$ and the above adjusted line is used to form the sum of squared error as:

$$
\begin{gathered}
\varepsilon^{2}=\sum_{i=1}^{n}\left(y_{i}-y_{r i}\right)^{2}, \quad \text { or } \\
\varepsilon^{2}=\sum_{i=1}^{n}\left(y_{i}-\hat{\beta}_{o} \cdot x_{i}-\hat{\alpha}\right)^{2}
\end{gathered}
$$

$i=1,2,3, \ldots, n$

Symbols with a ${ }^{\wedge}$ are sample estimates and from here to the end $\beta_{0}=\tan (\beta)$ also represents the regression coefficient; the ${ }^{\wedge}$ will be omitted from now on.

By making from (5) the derivatives of $\varepsilon^{2}$ relative to $\beta_{o}$ and $\alpha$ separately equal to zero and equating the resulting expressions for $\alpha$ one obtains:

$$
\alpha=1 / n\left(\sum_{i} y_{i}-\sum_{i} \beta_{o} \cdot x_{i}\right)
$$

$i=1,2, \ldots, n$, which, when replaced (6) in the first derivative produces:

$$
\begin{aligned}
\beta_{o}= & \left(n \sum y_{i} x_{i}-\sum y_{i} \sum x_{i}\right) / \\
& \left(n \sum x_{i}^{2}-\left(\sum x_{i}\right)^{2}\right) .
\end{aligned}
$$


By expanding the above expression (7) and by adding and subtracting in the denominator

$$
\left(\sum x_{i}\right)^{2}
$$

$\beta_{o}$ and $\rho_{c}$ can be expressed in terms of:

$$
\begin{gathered}
V A R[X]=\sum\left(x_{i}-\bar{x}\right)^{2}=\sigma^{2}\left(x_{i}\right), \\
\text { where } \bar{x}=1 / n \sum x_{i} \\
V A R[Y]=\sigma^{2}\left(y_{i}\right)
\end{gathered}
$$

and

$$
C O V[Y X]=n \sum x_{i} y_{i}-\sum x_{i} \sum y_{i}
$$

so that to obtain:

$$
\begin{aligned}
& \beta_{o}=\frac{C O V[Y X]}{\sqrt{V A R[X] V A R[X}} \text { and } \\
& \rho_{c}=\frac{C O V[Y X]}{\sqrt{V A R[X] V A R[Y]}}
\end{aligned}
$$

where $\beta_{o}$ is the regression coefficient and $\rho_{c}$ indicates correspondingly the collinearity coefficient, when time $t_{i}$ is taken linearly to represent the variable $x_{i}=t_{i}$.

\section{The $\boldsymbol{F}$ values}

Before showing the invariance of $\rho_{c}$ with $\beta_{o}$ it is convenient to define a function $F$ as follows. As the proximity $\ell$ and the collinearity $\rho_{c}$ coefficients are to be invariant with the values of the inclination angle $\beta$, it is convenient to define a variable $F$ that should also be invariant of the inclination $\beta$ and has the form:

$$
F=\ell \times \rho_{c} .
$$

From (13) $F$ relates the coefficients of proximity $\ell$ and collinearity $\rho_{c}$ and is a constant of each constrained planetary series, that are the sea level series of the PSMSL $y\left(t_{i}\right)$, which will be used here.

The same can be said about $F$ for a set of synthetic series $y 1\left(t_{i}\right)$, each series with $n=6$ to 60 values and with regression coefficients $\beta_{o}$ forced to vary from -40 to +40 , which were generated for this study.

To each assigned regression coefficient, a random value was synthetically added and also another random value added to the derived $y_{r i}\left(t_{i}\right)$ value, in order to produce series $y 1\left(t_{i}\right)$ free of constraints. Values of $F, \ell, \rho_{c}$ and $\beta$ were calculated for all synthetic $y 1\left(t_{i}\right)$, and the PSMSL series $y\left(t_{i}\right)$ and results were compared.

\section{RESULTS AND DISCUSSION}

The application of the expressions of previous sections, follows the methodology along which one has to correlate the straight line values $y_{r i}\left(t_{i}\right)$, given by its estimated coefficient of regres$\operatorname{sion} \beta_{o}=\tan (\beta)$, with the data, given by any function of time $y\left(t_{i}\right)$. In order to relate the $\beta_{o}$ and $\rho_{c}$ values, one can divide their expressions (12) above, to obtain:

$$
\beta_{o} / \rho_{c}=\frac{C O V[X, Y] /[\operatorname{Var}[X] \cdot \operatorname{Var}[Y]]^{1 / 2}}{\operatorname{COV}[X, Y] /[\operatorname{VAR}[X] \cdot \operatorname{VAR}[X]]^{1 / 2}}
$$

giving:

$$
\rho_{c} / \beta_{o}=\frac{s t d[X]}{s t d[Y]}=\frac{\beta_{o} \sigma\left(t_{i}\right)}{\sigma\left(y\left(t_{i}\right)\right)},
$$

but in (15) the standard deviation $\sigma\left(y\left(t_{i}\right)\right)$ has a real value that can, in all cases, be divided by $\sigma\left(t_{i}\right) \neq 0$, producing a real number $\beta^{\prime \prime}$, not always equal to $\beta_{o}$, and the above value is reduced to:

$$
\rho_{c}=\beta_{o} / \beta^{\prime \prime}=m_{o}
$$

where $m_{o}$ in (16) is a dimensionless constant, $\leq 1$. In this circumstance the collinearity coefficient $\rho_{c}$ is, for each regression line, invariant with the inclination, or rather, invariant with the regression coefficient given by $\beta_{o}=\tan (\beta)$, as sought for. For a given $\beta_{o}$ there will be always a number $\beta^{\prime \prime}$ to make the quotient equal to $m_{o}$.

The invariance of the collinearity coefficient $\rho_{c}$ with $\beta_{t}$ can also be seen in Figure 3, where their values for synthetic series are plotted. The distribution of $\rho_{c}$ and $\beta_{o}$ around a nearly diffuse figure characterizes the plotting of not co-variant values. In there, for each $\rho_{c}$, the $\beta_{o}$ values were forced by the computer to vary linearly from -40 to 40 .

The graph of $\rho_{c}$ and trends $\beta_{t}$ (mm/year) of real sea level planetary series shown in Figure 4 indicates, on the contrary, that although individually their collinearity and trends are statistically invariant and the graph should have had an apparent shape as Figure 3, they, as a set, do show to be planetary covariant variables. Meaning now that the values $\rho_{c}$ to $\beta_{t}$ of all series seem to be distributed in Figure 4 , as if they were covariant variables, due to what can be certain limits physically imposed on the series by the planet.

The gravitational field and the nearly constant mass of the planet Earth are apparently constraints that induce globally, somehow, the co-variance of the statistical variables of the series, which are, from their definition not co-variant variables. The study of this sort of say, elastic and gravitational induced dependence, of all PSMSL series may help to unveil the characteristics of the planetary constraints. 


\section{The $\boldsymbol{F}$ distribution graph}

A general characteristic is that for both, planetary and synthetic series, the distribution of $F$ values follows the assertions that the product $F=\ell \times \rho_{c}$ varies with $\ell$ and $\rho_{c}$ and conforms to be $F=0$, when $\ell$ is zero (and $\rho_{c}$ equals one) and turns to be $F=$ zero, when $\ell$ reaches its greatest values (and correspondingly $\rho_{c}$ is equal zero).

The invariance of $F$ with the trends $\beta$ of the series offers the opportunity of producing a graph with all PSMSL series, showing the world's distribution of permanent sea level measuring stations, which show a nearly constant distribution over the years (Fig. 5). The graph is nearly symmetrical, with a heavily populated positive side and also a very robust $F$ negative side, suggesting that might be an overall balance of their values.

Well known ports of Brest and San Francisco, which have the longest series, occupy the extreme positive values of the graph, but long series is not a determining factor of its positioning, as the port of Kungholmsfort, Scandinavia, series that is also long, occupies the near centre of the figure, $F=-1.441 \mathrm{~mm}$. It is clear then, that the $F$ values are not only invariant with the rate at which the sea level is increasing, or decreasing, but are also invariant with the length of the PSMSL series.

Occupying nearly permanent positions in the $F$ distribution of Planetary PSMSL series (Fig. 5) are the nominated ports of Kungsholmesport, $\left(56^{\circ} 06^{\prime} \mathrm{N}\right.$; $\left.15^{\circ} 35^{\prime} \mathrm{W}\right)$, Scandinavia, $F=$ $-1.441 \mathrm{~mm}$, of San Francisco, USA, $\left(37^{\circ} 48^{\prime} \mathrm{N} ; 122^{\circ} 28^{\prime} \mathrm{W}\right)$, $F=14.95 \mathrm{~mm}$, of Antofagasta, Chile (70² $\left.24^{\prime} \mathrm{W} ; 23^{\circ} 38^{\prime} \mathrm{S}\right)$,

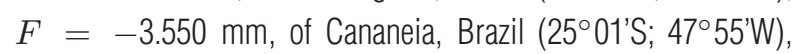
$F=4.565 \mathrm{~mm}$, of Balboa Panama, $\left(08^{\circ} 58^{\prime} \mathrm{N} ; 79^{\circ} 34^{\prime} \mathrm{W}\right) F=$ $8.774 \mathrm{~mm}$ and of Brest, France, $\left(48^{\circ} 23^{\prime} \mathrm{N}\right.$; $\left.04^{\circ} 30^{\prime} \mathrm{W}\right), F=$ $16.305 \mathrm{~mm}$. All PSMSL ports can also be identified in the distribution. Is out of the aims of present communication to examine further these points, but more work is under way in this direction.

\section{CONCLUDING REMARKS}

The search for invariants and co-variants in the annual mean sea level data of PSMSL (Permanent Service for the Mean Sea Level) of IAPSO (International Association for the Physical Sciences of the Oceans) lead us to the following conclusions.

1) The correlation coefficient $\rho_{c}$, taken as a measure of collinearity, and the mean distance $\ell$, taken as a measure of proximity of the discrete data points to the regression straight line, in time series, are both invariant with the inclination $\beta$ of the regression line relative to the Cartesian coordinated axes and, in consequence, their prod- uct is also independent. It was defined then the function $F=\rho_{c} \times \ell$ that is also invariant with $\beta$.

2) The statistical distribution of $F$ values of each PSMSL series, as well, is invariant with the trends $\beta_{t}$, the proximity $\ell$ values and also with the length (years) of the series.

3) In the distribution, ports of Brest and San Francisco, occupy extreme positions of distribution values ( $F=$ $16.305 \mathrm{~mm})$ and $(F=14.95 \mathrm{~mm}$ ) respectively, while station of Cananeia, Brazil, is well within a group of permanent sea level stations in a same bin near $F=4.565 \mathrm{~mm}$. The positions in the graph are nearly invariant with the time.

4) Besides these points, collinearity $\rho_{c}$ and trends $\beta_{t}$ of the series indicate also that although they are statistical invariants, they, as a global set, are planetary covariant variables, due to what seems to be the limits geo-physically imposed on planetary series such as the PSMSL sea level series.

5) The gravitational field and the nearly constant mass of the planet Earth are, apparently, constraints that induce the dependence of the estimates of statistical variables, which are, from their definition, statistical invariants, but that seem to be globally linearly distributed as covariant variables. The study of this induced dependence may help to unveil the characteristics of the planetary constraints.

\section{ACKNOWLEDGMENTS}

We are grateful to Dr. Philip Woodworth, Dr. Ian Vassie and Robert and Elaine Spencer of POL (Proudman Oceanographic Laboratory), Liverpool, UK, for their continued support and for providing the PSMSL series for this work. Dr. Joseph Harari critically revised the manuscript.

\section{REFERENCES}

IOC (Intergovernmental Oceanographic Commission). 2006. Manual on Sea Level Measurement and Interpretation. Manual and Guides 14. JCOMM Technical Report № 31. WM0/TD No 1339.80 pp.

JENKINS GM \& WATTS DG. 1968. Spectral Analysis and its Applications. Holden Day, London. 523 pp.

MESQUITA AR de. 1994. Variações do Nível do Mar de Longo Termo. Instituto de Estudos Avançados. Coleção Documentos. Série Ciências Ambientais. Universidade de São Paulo. SP, N. 20. 47-67. 
MESQUITA AR de. 2001. On the Regression $\times$ Correlation Plots of Geophysical Series. In: 7th Section of the IOC Group of Experts of GLOSS. IOC. WR V(180). 11 pp.

MESQUITA AR de \& LEITE JB de A. 1986. Sobre a Variabilidade do Nível Médio do Mar na Costa Sudeste do Brasil. Revista Brasileira de Geofísica, 4(2): 229-236.

MESQUITA AR de, FRANÇA CA de $S$ \& CORREA MA. 2001a. On the Collinearity and Proximity Coefficients of Planetary Series. In: $9^{\mathrm{a}}$ OESTE (Escola de Séries Temporais e Econometria). Proceedings... Associação Brasileira de Estatística. Belo Horizonte. MG. V(1). CD-ROM.

MESQUITA AR de, FRANÇA CA de S \& CORREA MA. 2001b. A Note on the Distances and Correlation of Sea Level Time Series. Afro-America GLOSS News. 5(1). Icone AAGN (Afro-America GLOSS News). Available on: <www.mares.io.usp.br>. Access on: 01/10/1999.

MESQUITA AR de, FRANÇA CA de $S$ \& CORREA MA. 2002. Proximity and Collinearity Coefficients of Time Series. Afro-America GLOSS
News. 6(1) Icone AAGN (Afro-America GLOSS News). Available on: $<$ www.mares.io.usp.br>. Access on: 01/11/2001.

MESQUITA AR de, FRANÇA CA de S \& CORREA MA. 2003a. Analysis of Sea Level Data of PSMSL Series. In: 10a Escola de Séries Temporais. Associação Brasileira de Estatística. São Pedro. SP. Vol(1). CD-ROM.

MESQUITA AR de, FRANÇA CA de S \& CORREA MA. 2003b. Proximity and Collinearity Coefficients: An Application to PSMSL Series. In: XXII General Assembly of the International Union of Geodesy and Geophysics. Sapporo. Japan. Book AV1. A 143 pp.

MESQUITA AR de, FRANCO A dos S, HARARI J \& FRANÇA CA de S. 2013. On sea level along the Brazilian coast. Rev. Brasileira de Geofísica, 31(Supl. 1): 33-42.

SPENCER EN \& WOODWORTH PL. 1993. Data Holdings of the Permanent Service for the Mean Sea Level. Bidston. Birkenhead. Merseyside, L437RA, UK. 81 pp.

Recebido em 23 novembro, 2010 / Aceito em 25 outubro, 2012

Received on November 23, 2010 / Accepted on October 25, 2012

\section{NOTES ABOUT THE AUTHORS}

Afrânio Rubens de Mesquita is a Physicist graduated from the Instituto de Física of the Universidade de São Paulo. Professor at the Instituto Oceanográfico of the Universidade de São Paulo and member of the Science History Center of the Universidade de São Paulo, PSMSL (Permanent Service for the Mean Sea Level) of IAPSO (International Association for the Physical Sciences of the Oceans), and MenGroup of Experts of GLOSS (Global Observing Sea Level System) of IOC (Intergovernmental Oceanographic Committee) of UNESCO.

Carlos Augusto de Sampaio França is a Physicist from the Instituto de Física da Universidade de São Paulo and a PhD in Physical Oceanography in the Instituto Oceanográfico of the Universidade de São Paulo, where works as a Physicist. Specializes in the treatment and analysis of altimetric sea measurements and the solution of the hydrodynamic equations in the Equatorial and South Atlantic.

Marco Antonio Corrêa is a Physicist from the Faculdade Oswaldo Cruz de São Paulo. Ph.D. in Physical Oceanography from the Instituto Oceanográfico from the Universidade de São Paulo. Is an associated researcher of the Company International Engineering and Applyied Sciences Associates. Works on coastal modeling and turbulent processes. 